\title{
Change in health care use after coordinated care planning: a quasi-experimental study
}

\author{
Iwona A. Bielska PhD, Kelly Cimek MSc, Dale Guenter MD MPH, Kelly O’Halloran RN MScN, \\ Chloe Nyitray BMath, Linda Hunter RN, Walter P. Wodchis PhD
}

See related research article at www.cmajopen.ca/lookup/doi/10.9778/cmajo.20170054

\section{Abstract}

Background: We sought to determine whether patients with a coordinated care plan developed using the Health Links model of care in the Hamilton Niagara Haldimand Brant Local Health Integration Network differed in their use of health care (no. of emergency department visits, inpatient admissions, length of inpatient stay) when compared with a matched control group of patients with no care plans.

Methods: We performed a propensity score-matched study of 12 months pre- and 12 months post-health care use. Patients who had a coordinated care plan that started between 2013 and 2015 were propensity score matched to patients in a control group. Patient information was obtained from Client Health and Related Information System, National Ambulatory Care Reporting System and Discharge Abstract Database. Differences in health care use pre- and post-index date were compared using the Wilcoxon signed-rank test. A negative binomial regression model was fit for each health care use outcome at 6 and 12 months post-index date.

Results: Six hundred coordinated care plan enrollees and 25449 potential control patients were included in the matching algorithm, which resulted in 548 matched pairs (91.3\%). Both groups showed decreases in health care use post-index date. Matched care plan enrollees had significantly fewer emergency department visits at 6 (incidence rate ratio [IRR] 0.81, 95\% confidence interval [CI] 0.72$0.91, p<0.01$ ) and 12 months post-index date (IRR $0.88,95 \% \mathrm{Cl} 0.79-0.99, p<0.05$ ) compared with the matched controls. Other use parameters were not significantly different between care plan enrollees and the control group.

Interpretation: Care plan enrollees show a decrease in the number of times they visit emergency departments, which may be attributed to integrated and coordinated care planning. This association should be examined to see whether these reductions persist for more than 1 year.

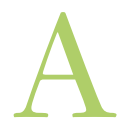

bout $5 \%$ of the population is estimated to account for up to $66 \%$ of total health care costs in Canada, resulting in these patients being described as "high-cost users."1-4 Previous studies of linked national survey and administrative data sets in Ontario, Manitoba and Saskatchewan suggest that these patients are often older adults with multimorbidity and low socioeconomic status. ${ }^{2,3,5,6}$ An analysis of Ontario data over 3 years showed that $31 \%$ of these patients will remain in the top $5 \%$ in terms of health care costs in subsequent years. ${ }^{7}$ Numerous jurisdictions have implemented coordinated care planning and case management models to address the needs of patients with complex conditions, as well as to support these patients in navigating the health care system and connecting them with community services. ${ }^{8-12}$ Studies on the effectiveness of coordinated care plans for high users of the health care system have yielded mixed results, with some showing only modest reductions in specific aspects of health care use. ${ }^{8,10,12}$ Data on the impact of coordinated care plans in Canadian settings are limited. A randomized controlled trial conducted in Montréal found that older adults enrolled in an integrated care program had a significant reduction in alternate level of care (ALC) inpatient days, with no differences seen in the number of acute

Competing interests: None declared.

This article has been peer reviewed.

Correspondence to: Iwona Bielska, iwona.bielska@Ihins.on.ca

CMAJ Open 2018. DOI:10.9778/cmajo.20170053 
inpatient days or emergency department visits when compared with a control group. ${ }^{12}$

In 2012, the Ontario Ministry of Health and Long-Term Care announced the creation of Health Links in each of the 14 Local Health Integration Networks (LHINs) to provide individualized coordinated care plans. ${ }^{9}, 13$ Eleven Health Links were established in the Hamilton Niagara Haldimand Brant LHIN in southern Ontario. ${ }^{14}$ The objectives of our study were to determine whether patients with a coordinated care plan within this LHIN differ in health care use at 6 and 12 months after the start of their care plan (post-care plan date) when compared with a propensity score matched control group. Our primary outcomes of interest were the number of emergency department visits, the number of inpatient admissions and the length of inpatient stays.

\section{Methods}

\section{Setting}

The Hamilton Niagara Haldimand Brant LHIN plans, funds and integrates the local health system to provide health care services to about 1.45 million people living in Hamilton, Burlington, the regional municipality of Niagara, and Haldimand, Norfolk and Brant counties. Coordinated care planning within the LHIN started in fiscal year 2013/14 and was fully implemented across the 11 Health Links during fiscal year 2015/16.

\section{Model of coordinated care planning}

The target population for Health Links is the top 5\% of high health care users in the province and includes patients with multiple comorbidities and complex health needs. ${ }^{15}$ In the LHIN under study, priority is given to patients who have had a minimum of 5 emergency department visits in the previous year. The goal of the Health Links model of care is to provide patient-centred, coordinated and efficient care through a single point of contact. Emphasis is placed on patient engagement and identifying the actions and goals that are the most meaningful to the patient. Coordinated care planning strengthens communication between patients and their providers, and within a patient's multidisciplinary care team, improves the patient's journey along the continuum of care and is intended to reduce unnecessary visits to the hospital. A selection of innovative practices entitled Coordinated Care Management are available to support Health Links through Health Quality Ontario. ${ }^{16}$ Patients who had a history of 5 or more emergency department visits and who may have had inpatient admissions within the past year were identified and assessed for eligibility for a coordinated care plan within the Health Links model of care. Priority focus populations included patients with mental health conditions or addictions, patients with frailty and patients receiving palliative care. Patients at risk for admission to hospital were also considered. These populations included patients with unstable conditions or declining health, as well as those with challenges around having low support, poor health literacy, low household income, housing issues and transportation problems. The list of high health care users within the LHIN was prepared using data housed at the Integrated Decision Support (IDS), a data warehouse and business intelligence tool hosted by Hamilton Health Sciences. ${ }^{17}$ Furthermore, hospital sites within the LHIN have real-time identification of patients. Patients who are deemed eligible are invited to participate. If the patient consents to enrolment, the coordinated care plan is started and engages the patient's primary care physician, home services and community partners.

\section{Participants}

Patients in the LHIN aged 16 years and older who had a coordinated care plan ("care plan enrollees") that started between Oct. 1, 2013, and Sept. 30, 2015, were eligible for inclusion. The potential control pool ("potential control group") comprised patients (age $\geq 16$ years) residing in the LHIN who met the enrolment criteria for Health Links, having had 5 or more emergency department visits within a fiscal year, applied across fiscal years 2013/14, 2014/15 and $2015 / 16$. Patients were removed from the control pool if they had ever participated in a coordinated care plan through Health Links. Eligible members of the control group were randomly assigned proxy care plan index dates that mimicked the distribution of the index dates of care plan enrollees to calculate health care use for this group. Because the primary outcome measures were first compared at 6 months' postindex date (start date of the coordinated care plan), data from care plan enrollees and potential members of the control group who had died within this time frame were excluded from the analysis. In addition, patients admitted to long-term care post-index date were excluded because their care was no longer coordinated by Health Links.

\section{Measures and sources of data}

Our primary outcomes of interest for the analysis were the number of emergency department visits, the number of inpatient admissions and the length of inpatient stays. We chose these measures because either they were identified as priorities for the Health Links model of care or they have been identified as being affected by care planning in previous studies. ${ }^{15,18-20}$ Information was obtained from administrative databases using IDS. ${ }^{17}$ Data captured in IDS includes health care encounters within the LHIN and all neighbouring LHINs (Erie St. Clair, Mississauga Halton, South West, Toronto Central and Waterloo Wellington). Information within the databases housed at IDS is directly provided through hospital or LHIN submissions. Information on patient characteristics, such as sex, age, Health Link geography, coordinated care plan index date, home care client status and long-term care residence came from the Client Health and Related Information System (CHRIS) and the Health Links internal reporting databases for patients with coordinated care plans. ${ }^{21}$ Demographic information was cross-referenced with data from the National Ambulatory Care Reporting System (NACRS), ${ }^{22}$ and the Canadian Institute of Health Information Discharge Abstract Database (DAD). ${ }^{23}$ Data on ambulatory care were abstracted from the NACRS, ${ }^{22}$ while data on inpatient admis- 
sions, length of inpatient stay, and Charlson comorbidity index ${ }^{24}$ were obtained from the DAD. ${ }^{23}$ Information from NACRS and DAD was used to determine whether patients had one or more chronic conditions tracked by the LHIN Health Links based on the International Statistical Classification of Diseases and Related Health Problems, 10th Revision, Canada (ICD-10-CA) diagnostic codes ${ }^{25}$ (Appendix 1, available at www.cmajopen.ca/content/6/2/E218/suppl/DC1): arthritis and related disorders, chronic obstructive pulmonary disease (COPD), congestive heart failure, diabetes, neoplasm, psychiatric conditions, renal failure or substance-related disorders. ${ }^{26}$ Care plan enrollees were identified through each Health Link's standardized reporting. Information across the databases was linked using an anonymous and unique master patient index number.

\section{Statistical analysis}

Care plan enrollees were propensity score matched to potential members of the control group within the LHIN. Propensity score analysis was done to determine the characteristics that predict the probability of enrolment in a care plan among high users of health care services. Propensity scores were calculated using a stepwise logistic regression model (significance level for entry and stay was 0.15 ) with the following variables included in the final model: age, Health Link geography, fiscal year quarter of index date, presence of home and community services pre-index date, number of emergency department visits and inpatient stays in the 12 months pre-index date and the presence of chronic health conditions (congestive heart failure, COPD, psychiatric conditions, substance-related disorders). Care plan enrollees were matched to potential members of the control group using 1:1 greedy matching through the \%gmatch macro from the Mayo Clinic within 0.2 standard caliper widths of the propensity score. ${ }^{28,29}$ The participants were exact matched on sex, whether they had 12 months of post-index data available, and whether they had congestive heart failure or COPD diagnoses, because patients with these conditions were focus populations. Participants were matched within 1 standard deviation of the care plan enrollees' mean for health care use (no. of emergency department visits and inpatient stays within 12 months pre-index date) and 2 standard deviations of the care plan enrollees' mean for age. The distribution of characteristics between the matched care plan enrollees and patients in the control group was evaluated with a standardized difference of $10 \%$ or less showing balance.

Differences in health care use 12 months pre- and 12 months post-index date were compared between the two groups using the Wilcoxon signed-rank test. A negative binomial regression model was fit for each health care use outcome (no. of emergency department visits, no. of inpatient admissions and inpatient length of stay [d]) at 6 and 12 months post-index date, controlling for the respective baseline health care use at 12 months pre-index date. We selected this modelling strategy because of the overdispersion we saw in the health care use variables. For each of the models, the Pearson $\chi^{2}$ statistic and scaled deviance suggested good model fit. The results between groups are reported as means adjusted for pre-index date health care use and incidence rate ratios (ratio of the adjusted means of the 2 groups). A $p$ value of less than 0.05 was considered to be significant. All analyses were performed using SAS version 9.4 (SAS Institute, Cary, NC).

\section{Ethics approval}

The analysis was conducted using administrative data as part of a quality improvement project and did not include personal health information. As such, it was reviewed by the Privacy and Freedom of Information Office at Hamilton Health Sciences and was determined to not require research ethics board approval. The STROBE Checklist was followed in the preparation of this paper. ${ }^{27}$

\section{Results}

We identified 704 patients, aged 16 years and older, who were enrolled on a coordinated care plan between Sept. 1, 2013, and Sept. 30, 2015 (Figure 1). Of the care plan enrollees, 104 were ineligible for inclusion because they had been admitted to long-term care after their care plan was developed $(n=10)$ or they had died before the initial analysis at 6 months $(n=$ 94). Among 27257 potential members of the control group, 1808 were ineligible for inclusion because they had been admitted to long-term care after their care plan index date $(n$ $=284$ ) or they had died before the initial analysis at 6 months $(n=1524)$. In total, 600 coordinated care plan enrollees and 25449 potential members of the control group were eligible for inclusion in the propensity score matching algorithm, which resulted in 548 matched pairs $(91.3 \%$ of care plan enrollees) with at least 6 months of post-index data. Of note, at 12 months post-index date, 511 care plan enrollees and their matched controls were still alive. Table 1 presents the descriptive characteristics of the matched sample by group at baseline. Standardized differences between the 2 groups were less than $10 \%$, suggesting a good balance of characteristics.

The standardized differences for the unmatched care plan enrollees $(n=52)$ and the unmatched patients from the potential control group $(n=24901)$ were compared with the matched care plan enrollees (Table 2). Overall, the unmatched controls tended to be female, younger, had fewer comorbidities, and experienced lower baseline health care use than did matched care plan enrollees. The opposite was true of unmatched care plan enrollees, who tended to be male, older, had more comorbidities, and experienced higher health care use than did matched care plan enrollees. Table 3 provides additional detail on health care use for unmatched care plan enrollees and shows that this group also had decreases in health care use after the index date.

Table 4 presents the unadjusted mean and median health care use within each of the groups (matched care plan enrollees and matched controls), comparing values 12 months before and after the index date. Table 5 presents the adjusted means at 6 months post-index date for both groups and outlines the incidence rate ratios (IRRs), controlling for pre- 


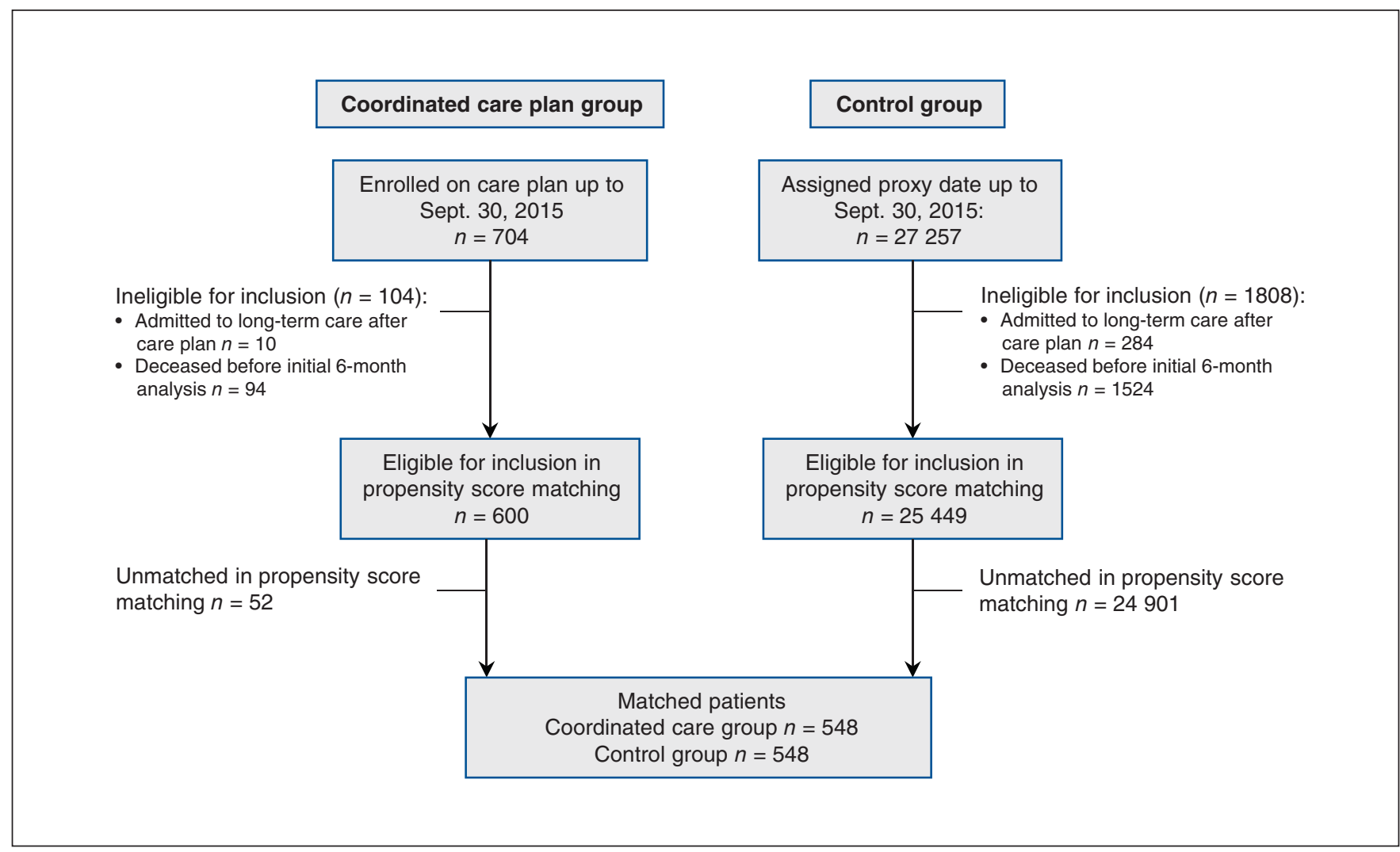

Figure 1: Flow of participants through the study.

index date health care use. Matched care plan enrollees were found to have significantly fewer emergency department visits 6 months post-index date (IRR $0.81,95 \%$ confidence interval [CI] $0.72-0.91, p<0.01)$ compared with the matched control group. Similar findings were seen at 12 months post-index date (IRR 0.88, 95\% CI 0.79-0.99, $p<0.05$ ) (Table 6). No significant differences were seen among the groups in the number of inpatient hospital admissions or inpatient length of stay (total, acute or ALC). On further analysis, when the change from baseline was examined, no significant differences were found between the groups, although matched care plan enrollees tended to have greater decreases in emergency department visits and inpatient admissions.

\section{Interpretation}

In this quasi-experimental study of health care use among propensity-score matched patients with a coordinated care plan compared with a control group, both groups of patients had decreases in health care use over 12 month period post-index date. In the comparative analysis, matched care plan enrollees had a larger and significant decrease in the number of emergency department visits at both 6 and 12 months post-index date compared with the control patients, when adjusting for baseline emergency department use. No differences were seen in the number of inpatient hospital admissions or the length of stay in hospital between groups post-index date. These findings are clin- ically relevant because one of the objectives of coordinated care planning is to reduce the number of emergency department visits for conditions that can be better addressed in other health care settings. For this reason, it seems that care plan enrollees are decreasing their frequency of emergency department visits, which may be attributed to integrated and coordinated care planning.

Our results suggest that the number of emergency department visits was lower among care plan enrollees than among matched controls. A similar finding was not seen for hospital admissions. A possible explanation may be that coordinated care planning had the greatest effect on reducing the number of less serious incidents that did not need an emergency visit, such as managing minor and moderate issues in the community. One of the reasons that the high care controls improved over time is high use is not a permanent condition for most people. A previous study of health care use among residents of Ontario showed that, of patients who were identified as in the 95 th percentile or greater in terms of health spending in 2009, about $38 \%$ were classified as below the 90 th percentile by $2011 .^{7}$

Our results are promising in comparison with those of similar interventions. A recent analysis evaluated the effect of case management by multidisciplinary teams on health care use among high-risk patients in the United Kingdom 1 year after the implementation of the service compared with a propensity-scored matched control group. ${ }^{8}$ The authors concluded that the intervention did not meet its objectives of 
Table 1: Baseline characteristics of care plan enrollees and matched controls

\begin{tabular}{|c|c|c|c|}
\hline Characteristic & $\begin{array}{l}\text { Care plan enrollees, no. (\%)* } \\
\qquad n=548\end{array}$ & $\begin{array}{c}\text { Controls, no. }(\%)^{*} \\
n=548\end{array}$ & $\begin{array}{l}\text { Standardized } \\
\text { difference }\end{array}$ \\
\hline Female sex & $290(52.9)$ & $290(52.9)$ & 0.00 \\
\hline Age, yr, mean \pm SD & $67.7 \pm 17.1$ & $67.9 \pm 17.3$ & 0.01 \\
\hline \multicolumn{4}{|l|}{ Health Link } \\
\hline Brant Six Nations & $42(7.7)$ & $42(7.7)$ & 0.00 \\
\hline Burlington & $57(10.4)$ & $51(9.3)$ & 0.03 \\
\hline Haldimand & $38(6.9)$ & $32(5.8)$ & 0.04 \\
\hline Hamilton Central & $111(20.3)$ & $120(21.9)$ & 0.03 \\
\hline Hamilton East & $51(9.3)$ & $59(10.8)$ & 0.04 \\
\hline Hamilton West & $35(6.4)$ & $38(6.9)$ & 0.02 \\
\hline Niagara North East & $61(11.1)$ & $53(9.7)$ & 0.04 \\
\hline Niagara North West & $52(9.5)$ & $50(9.1)$ & 0.01 \\
\hline Niagara South East & $9(1.6)$ & $8(1.5)$ & 0.01 \\
\hline Niagara South West & $41(7.5)$ & $49(8.9)$ & 0.04 \\
\hline Norfolk & $51(9.3)$ & $46(8.4)$ & 0.03 \\
\hline \multicolumn{4}{|c|}{ Coordinated care plan or proxy index fiscal year and quarter } \\
\hline 2013/14 Q3 & $7(1.3)$ & $6(1.1)$ & 0.01 \\
\hline 2013/14 Q4 & $8(1.5)$ & $12(2.2)$ & 0.05 \\
\hline $2014 / 15$ Q1 & $13(2.4)$ & $9(1.6)$ & 0.04 \\
\hline $2014 / 15$ Q2 & $34(6.2)$ & $30(5.5)$ & 0.03 \\
\hline 2014/15 Q3 & $46(8.4)$ & $44(8.0)$ & 0.01 \\
\hline $2014 / 15$ Q4 & $128(23.4)$ & $122(22.3)$ & 0.02 \\
\hline 2015/16 Q1 & $163(29.7)$ & $162(29.6)$ & 0.00 \\
\hline 2015/16 Q2 & $149(27.2)$ & $163(29.7)$ & 0.05 \\
\hline \multicolumn{4}{|l|}{ Comorbid conditions } \\
\hline Arthritis & $271(49.5)$ & $271(49.5)$ & 0.00 \\
\hline COPD & $24(44.5)$ & $244(44.5)$ & 0.00 \\
\hline Congestive heart failure & $182(33.2)$ & $182(33.2)$ & 0.00 \\
\hline COPD and congestive heart failure & $103(18.8)$ & $103(18.8)$ & 0.00 \\
\hline Diabetes & $219(40.0)$ & $206(37.6)$ & 0.04 \\
\hline Neoplasm & $97(17.7)$ & $108(19.7)$ & 0.04 \\
\hline Psychiatric condition & $213(38.9)$ & $214(39.1)$ & 0.00 \\
\hline Renal failure & $173(31.6)$ & $161(29.4)$ & 0.04 \\
\hline Substance-related disorders & $122(22.3)$ & $121(22.1)$ & 0.00 \\
\hline \multicolumn{4}{|l|}{ Charlson comorbidity index } \\
\hline 0 & $345(63.0)$ & $330(60.2)$ & 0.05 \\
\hline 1 & $95(17.3)$ & $100(18.3)$ & 0.02 \\
\hline 2 & $61(11.1)$ & $54(9.9)$ & 0.03 \\
\hline$\geq 3$ & $47(8.6)$ & $64(11.7)$ & 0.09 \\
\hline Home and community care before index date & $274(50.0)$ & $266(48.5)$ & 0.02 \\
\hline \multicolumn{4}{|l|}{ Emergency department visits, no., mean \pm SD } \\
\hline 6 mo pre-index date & $4.3 \pm 5.1$ & $4.3 \pm 4.2$ & 0.00 \\
\hline 12 mo pre-index date & $7.6 \pm 7.8$ & $7.4 \pm 7.3$ & 0.02 \\
\hline \multicolumn{4}{|l|}{ Inpatient admissions, mean \pm SD } \\
\hline 6 mo pre-index date & $1.4 \pm 1.5$ & $1.3 \pm 1.4$ & 0.00 \\
\hline 12 mo pre-index date & $2.3 \pm 2.0$ & $2.2 \pm 2.0$ & 0.07 \\
\hline \multicolumn{4}{|l|}{ Inpatient length of stay, $d$, mean \pm SD } \\
\hline 6 mo pre-index date total & $11.6 \pm 19.4$ & $11.8 \pm 21.5$ & 0.01 \\
\hline 12 mo pre-index date total & $19.6 \pm 27.3$ & $18.7 \pm 28.3$ & 0.03 \\
\hline 6 mo pre-index date acute & $9.4 \pm 14.1$ & $9.6 \pm 13.9$ & 0.01 \\
\hline 12 mo pre-index date acute & $15.9 \pm 19.2$ & $15.5 \pm 20.6$ & 0.02 \\
\hline 6 mo pre-index date ALC & $2.2 \pm 10.2$ & $2.3 \pm 12.2$ & 0.01 \\
\hline 12 mo pre-index date ALC & $3.7 \pm 15.6$ & $3.2 \pm 13.8$ & 0.04 \\
\hline
\end{tabular}




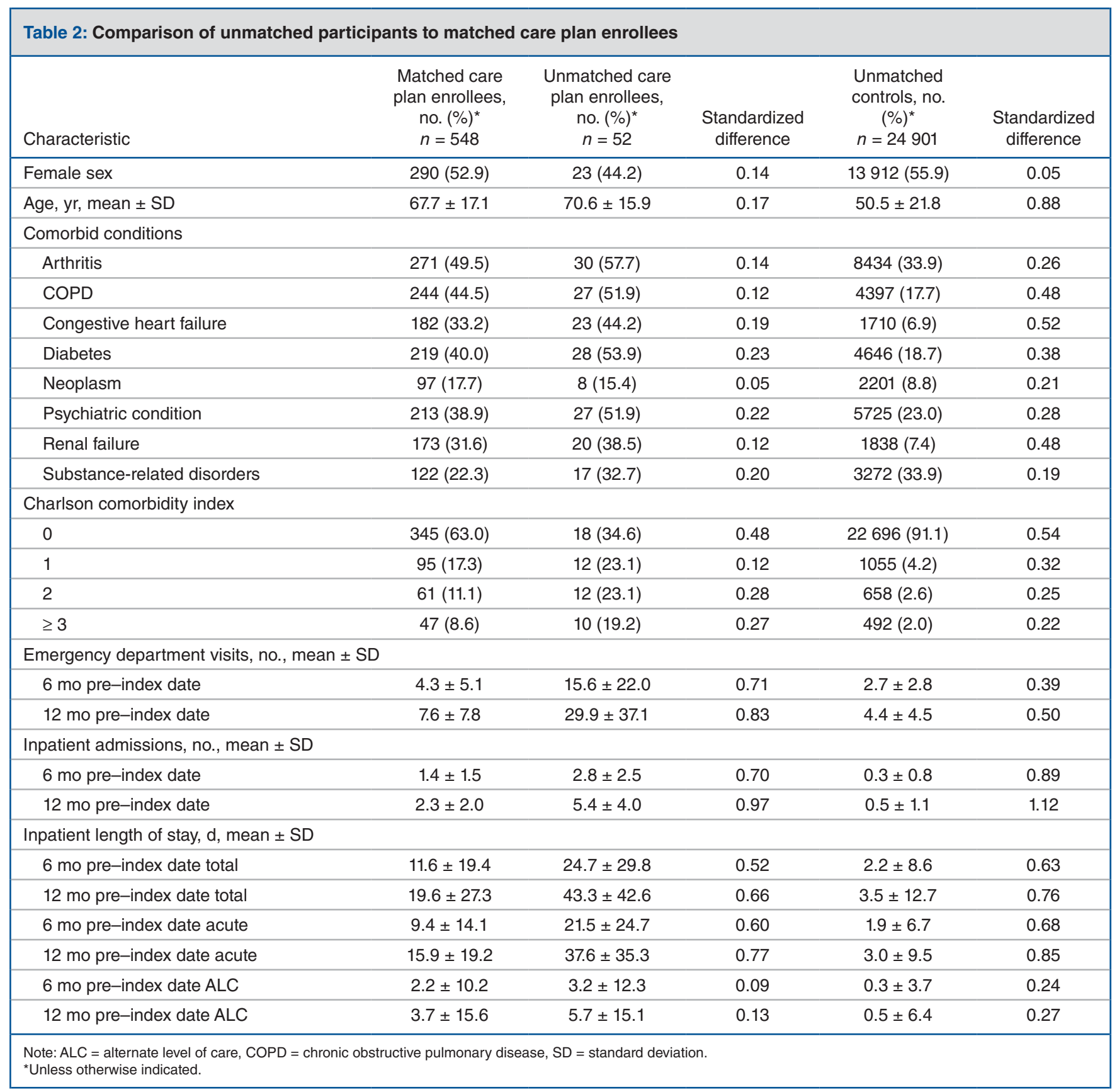

reducing health care use, having observed minimal but not clinically relevant findings. A randomized controlled trial that included older adults with disabilities living in Montréal that assessed an integrated care program found that the program resulted in greater accessibility to home health care and a reduction in ALC inpatient days. ${ }^{12}$ However, the number of emergency department visits or days of acute care in hospital did not differ between groups. In a large randomized controlled trial of 15 care coordination programs across the United States, no overall differences in hospital admissions were seen between the treatment group and patients who received usual care. ${ }^{30}$

\section{Limitations}

Although coordinated care plans follow a standard framework in Ontario, they are meant to evolve in an iterative process for each patient, thereby being individualized to each enrollee's personal goals and unique circumstances. For this reason, the population with a coordinated care plan may not be a homogeneous entity within the LHIN under study. Patients with care plans have a wide range of chronic conditions. In addition, people in the potential control pool may have not yet been approached for enrolment in a coordinated care plan or had been invited to participate, but declined. Of note, it is evident that during the first 6 months 
Table 3: Unadjusted means and medians at pre- and post-index date for unmatched care plan enrollees

\begin{tabular}{|c|c|c|c|c|c|c|c|c|}
\hline \multirow[b]{2}{*}{ Characteristic } & \multicolumn{2}{|c|}{$\begin{array}{c}12 \text { mo pre-index date } \\
n=52\end{array}$} & \multicolumn{2}{|c|}{$\begin{array}{c}12 \text { mo pre-index date* } \\
n=42\end{array}$} & \multicolumn{2}{|c|}{$\begin{array}{c}6 \text { mo pre-index date } \\
n=52\end{array}$} & \multicolumn{2}{|c|}{$\begin{array}{c}12 \text { mo pre-index date } \\
n=42\end{array}$} \\
\hline & Mean \pm SD & $\begin{array}{l}\text { Median } \\
(\text { IQR })\end{array}$ & Mean \pm SD & $\begin{array}{l}\text { Median } \\
\text { (IQR) }\end{array}$ & Mean \pm SD & $\begin{array}{l}\text { Median } \\
\text { (IQR) }\end{array}$ & Mean \pm SD & $\begin{array}{l}\text { Median } \\
(\text { IQR })\end{array}$ \\
\hline $\begin{array}{l}\text { Emergency } \\
\text { department visits }\end{array}$ & $29.9 \pm 37.1$ & $13.0(30.5)$ & $35.1 \pm 39.5$ & $15.0(42.0)$ & $14.2 \pm 26.9$ & $4.0(8.5)$ & $26.5 \pm 42.2$ & $6.5(32.0)$ \\
\hline $\begin{array}{l}\text { Inpatient hospital } \\
\text { admissions }\end{array}$ & $5.4 \pm 4.0$ & $5.0(6.0)$ & $5.4 \pm 4.3$ & $5.0(7.0)$ & $1.5 \pm 1.9$ & $1.0(3.0)$ & $2.4 \pm 3.1$ & $1.0(4.0)$ \\
\hline $\begin{array}{l}\text { Total inpatient } \\
\text { length of stay }\end{array}$ & $43.3 \pm 42.6$ & $33.0(45.5)$ & $45.0 \pm 45.9$ & $35.0(51.0)$ & $21.7 \pm 38.7$ & $2.0(23.5)$ & $31.8 \pm 55.3$ & $10.0(28.0)$ \\
\hline $\begin{array}{l}\text { Acute inpatient } \\
\text { length of stay }\end{array}$ & $37.6 \pm 35.3$ & $31.0(47.0)$ & $38.6 \pm 38.0$ & $31.0(51.0)$ & $12.9 \pm 20.3$ & $2.0(18.5)$ & $20.4 \pm 35.8$ & $7.5(17.0)$ \\
\hline $\begin{array}{l}\text { ALC inpatient } \\
\text { length of stay }\end{array}$ & $5.7 \pm 15.1$ & $0.0(2.5)$ & $6.5 \pm 16.6$ & $0.0(4.0)$ & $8.8 \pm 25.0$ & $0.0(0.0)$ & $11.4 \pm 28.6$ & $0.0(8.0)$ \\
\hline
\end{tabular}

Table 4: Unadjusted means and medians at 12 months pre- and post-index date by group for patients alive at 12 months post-index date

\begin{tabular}{|c|c|c|c|c|c|c|c|}
\hline \multirow[b]{2}{*}{ Characteristic } & & \multicolumn{2}{|c|}{12 mo pre-index date } & \multicolumn{2}{|c|}{12 mo post-index date } & \multirow[b]{2}{*}{$\begin{array}{c}\text { Mean } \\
\text { difference } \pm \text { SD }\end{array}$} & \multirow[b]{2}{*}{$p$ value* } \\
\hline & & Mean \pm SD & $\begin{array}{l}\text { Median } \\
\text { (IQR) }\end{array}$ & Mean \pm SD & $\begin{array}{l}\text { Median } \\
\text { (IQR) }\end{array}$ & & \\
\hline \multirow[t]{2}{*}{$\begin{array}{l}\text { Emergency } \\
\text { department visits }\end{array}$} & $\begin{array}{l}\text { Matched care } \\
\text { plan enrollees } †\end{array}$ & $7.7 \pm 8.0$ & $6.0(6.0)$ & $5.6 \pm 7.8$ & $3.0(6.0)$ & $-2.07 \pm 6.51$ & $<0.01$ \\
\hline & $\begin{array}{l}\text { Matched } \\
\text { controls† }\end{array}$ & $7.4 \pm 7.4$ & $6.0(5.0)$ & $5.6 \pm 6.8$ & $4.0(5.0)$ & $-1.84 \pm 6.81$ & $<0.01$ \\
\hline \multirow[t]{2}{*}{$\begin{array}{l}\text { Inpatient } \\
\text { admissions }\end{array}$} & $\begin{array}{l}\text { Matched care } \\
\text { plan enrollees } †\end{array}$ & $2.3 \pm 2.0$ & $2.0(2.0)$ & $1.4 \pm 2.1$ & $1.0(2.0)$ & $-0.83 \pm 2.27$ & $<0.01$ \\
\hline & $\begin{array}{l}\text { Matched } \\
\text { controls† }\end{array}$ & $2.1 \pm 2.0$ & $2.0(2.0)$ & $1.4 \pm 1.8$ & $1.0(2.0)$ & $-0.73 \pm 2.31$ & $<0.01$ \\
\hline \multirow[t]{2}{*}{$\begin{array}{l}\text { Total inpatient } \\
\text { length of stay }\end{array}$} & $\begin{array}{l}\text { Matched care } \\
\text { plan enrollees } †\end{array}$ & $18.7 \pm 24.8$ & $10.0(23.0)$ & $12.7 \pm 27.2$ & $2.0(16.0)$ & $-6.06 \pm 33.47$ & $<0.01$ \\
\hline & $\begin{array}{l}\text { Matched } \\
\text { controls† }\end{array}$ & $18.0 \pm 27.6$ & $9.0(24.0)$ & $12.6 \pm 25.4$ & $3.0(15.0)$ & $-5.38 \pm 34.96$ & $<0.01$ \\
\hline \multirow[t]{2}{*}{$\begin{array}{l}\text { Acute inpatient } \\
\text { length of stay }\end{array}$} & $\begin{array}{l}\text { Matched care } \\
\text { plan enrollees } †\end{array}$ & $15.6 \pm 19.2$ & $9.0(21.0)$ & $9.7 \pm 16.6$ & $1.0(13.0)$ & $-5.87 \pm 21.87$ & $<0.01$ \\
\hline & $\begin{array}{l}\text { Matched } \\
\text { controls† }\end{array}$ & $14.9 \pm 20.0$ & $8.0(20.0)$ & $9.4 \pm 16.8$ & $3.0(12.0)$ & $-5.51 \pm 23.45$ & $<0.01$ \\
\hline \multirow[t]{2}{*}{$\begin{array}{l}\text { ALC inpatient length } \\
\text { of stay }\end{array}$} & $\begin{array}{l}\text { Matched care } \\
\text { plan enrollees† }\end{array}$ & $3.2 \pm 11.5$ & $0.0(0.0)$ & $3.0 \pm 16.7$ & $0.0(0.0)$ & $-0.19 \pm 20.21$ & 0.14 \\
\hline & $\begin{array}{l}\text { Matched } \\
\text { controls† }\end{array}$ & $3.1 \pm 13.7$ & $0.0(0.0)$ & $3.2 \pm 14.9$ & $0.0(0.0)$ & $0.12 \pm 20.03$ & 0.93 \\
\hline
\end{tabular}

after the index date, more care plan enrollees had died $(13.4 \%$ v. $5.6 \%)$ or been admitted to long-term care $(9.6 \%$ v. $1.0 \%)$ compared with potential controls. This may suggest that care plan enrollees have more complex medical and social requirements. Even though the matched care plan enrollees and controls were equivalent in terms of measured baseline characteristics, they may have differed in unmeasured factors, such as social determinants of health, which could have led to a masking of the true effect of the care plan. Finally, it is important to note that $8.3 \%$ of the care 


\begin{tabular}{|c|c|c|c|}
\hline Characteristic & $\begin{array}{l}\text { Adjusted mean* } \\
(95 \% \mathrm{Cl}) \\
\text { matched care plan } \\
\text { enrollees } \\
n=548\end{array}$ & $\begin{array}{l}\text { Adjusted mean* } \\
(95 \% \mathrm{Cl}) \\
\text { matched controls } \\
n=548\end{array}$ & $\begin{array}{l}\text { Incidence rate ratio } \\
(95 \% \mathrm{Cl}) \\
\text { reference group: } \\
\text { matched controls }\end{array}$ \\
\hline $\begin{array}{l}\text { Emergency } \\
\text { department visits }\end{array}$ & $2.52(2.32-2.74)$ & $3.11(2.87-3.37)$ & $0.81 \dagger(0.72-0.91)$ \\
\hline $\begin{array}{l}\text { Inpatient } \\
\text { admissions }\end{array}$ & $0.73(0.65-0.83)$ & $0.84(0.74-0.95)$ & $0.87(0.73-1.04)$ \\
\hline $\begin{array}{l}\text { Total inpatient } \\
\text { length of stay }\end{array}$ & $7.94(6.39-9.86)$ & $8.02(6.46-9.96)$ & $0.99(0.73-1.34)$ \\
\hline $\begin{array}{l}\text { Acute inpatient } \\
\text { length of stay }\end{array}$ & $5.78(4.71-7.08)$ & $5.78(4.71-7.08)$ & $1.00(0.75-1.33)$ \\
\hline $\begin{array}{l}\text { ALC inpatient length } \\
\text { of stay }\end{array}$ & $2.05(1.18-3.58)$ & $2.19(1.26-3.81)$ & $0.94(0.43-2.06)$ \\
\hline \multicolumn{4}{|c|}{$\begin{array}{l}\text { Note: } \mathrm{ALC}=\text { alternate level of care, } \mathrm{Cl}=\text { confidence interval. } \\
\text { *All models are adjusted for baseline } 12 \text {-month use for given outcome measure. } \\
\dagger p<0.01 \text {. }\end{array}$} \\
\hline
\end{tabular}

\begin{tabular}{|c|c|c|c|}
\hline \multicolumn{4}{|c|}{$\begin{array}{l}\text { Table 6: Adjusted means and incidence rate ratios for 12-month health care use by } \\
\text { group }\end{array}$} \\
\hline Characteristic & $\begin{array}{l}\text { Adjusted mean* } \\
(95 \% \mathrm{Cl}) \\
\text { matched care plan } \\
\text { enrollees } \\
n=511\end{array}$ & $\begin{array}{l}\text { Adjusted mean* } \\
(95 \% \mathrm{Cl}) \\
\text { matched controls } \\
n=511\end{array}$ & $\begin{array}{l}\text { Incidence rate ratio } \\
(95 \% \mathrm{Cl}) \\
\text { (reference: matched } \\
\text { controls) }\end{array}$ \\
\hline $\begin{array}{l}\text { Emergency } \\
\text { department visits }\end{array}$ & $4.62(4.26-5.01)$ & $5.25(4.85-5.68)$ & $0.88 †(0.79-0.99)$ \\
\hline $\begin{array}{l}\text { Inpatient } \\
\text { admissions }\end{array}$ & $1.27(1.13-1.43)$ & $1.32(1.18-1.49)$ & $0.96(0.82-1.13)$ \\
\hline $\begin{array}{l}\text { Total inpatient } \\
\text { length of stay }\end{array}$ & $11.80(9.78-14.23)$ & $12.18(10.10-14.69)$ & $0.97(0.74-1.26)$ \\
\hline $\begin{array}{l}\text { Acute inpatient } \\
\text { length of stay }\end{array}$ & $8.79(7.36-10.49)$ & $9.05(7.58-10.81)$ & $0.97(0.76-1.25)$ \\
\hline $\begin{array}{l}\text { ALC inpatient length } \\
\text { of stay }\end{array}$ & $2.98(1.88-4.71)$ & $3.16(2.00-5.00)$ & $0.94(0.49-1.80)$ \\
\hline \multicolumn{4}{|c|}{$\begin{array}{l}\text { Note: } \mathrm{ALC}=\text { alternate level of care, } \mathrm{Cl}=\text { confidence interval. } \\
{ }^{*} \text { All models are adjusted for baseline } 12 \text {-month use for given outcome measure. } \\
t p<0.05 \text {. }\end{array}$} \\
\hline
\end{tabular}

plan enrollees were not successfully matched to a control. This may affect the generalizability of the results to all Health Links enrollees, particularly those who are higher users before enrolment in a coordinated care plan.

\section{Conclusion}

The potential long-term effects of coordinated care planning on health care use will be examined over time as the Health Links model of care evolves and additional patients are enrolled. In addition, further work is being undertaken to explore other aspects of care planning in this LHIN, including the patient experience of enrollees and the return-oninvestment of the Health Links model of care. Our results show that patients on coordinated care plans in this LHIN had fewer emergency department visits as early as 6 months after enrolment when compared with a propensity scorematched control group. This relationship should be examined in the future to see if these reductions persist past 1 year.

\section{References}

1. Reid R, Evans R, Barer M, et al. Conspicuous consumption: characterizing high users of physician services in one Canadian province. 7 Health Serv Res Policy 2003;8:215-24.

2. Rosella LC, Fitzpatrick T, Wodchis WP, et al. High-cost health care users in Ontario, Canada: demographic, socio-economic, and health status characteristics. BMC Health Serv Res 2014;14:532.

3. Rais S, Nazerian A, Ardal S, et al. High-cost users of Ontario's healthcare services. Healthc Policy 2013;9:44-51. 
4. Briggs T, Burd M, Fransoo R. Identifying high users of healthcare in British Columbia, Alberta and Manitoba. Healtbc Pap 2014;14:31-6, discussion 58-60.

5. Lemstra M, Mackenbach J, Neudorf C, et al. High health care utilization and costs associated with lower socio-economic status: results from a linked dataset. Can 7 Public Health 2009;100:180-3.

6. Roos N, Burchill C, Carriere K. Who are the high hospital users? A Canadian case study. 7 Health Serv Res Policy 2003;8:5-10.

7. Wodchis WP, Austin PC, Henry DA. A 3-year study of high-cost users of health care. CMA7 2016;188:182-8.

8. Stokes J, Kristensen SR, Checkland K, et al. Effectiveness of multidisciplinary team case management: difference-in-differences analysis. BMF Open 2016;6:e010468.

9. Transforming Ontario's health care system. Toronto: Ministry of Health and Long-Term Care; 2016. Available: www.health.gov.on.ca/en/pro/programs/ transformation/community.aspx (accessed 2016 Nov. 21).

10. Casas A, Troosters T, Garcia-Aymerich J, et al.; members of the CHRONIC Project. Integrated care prevents hospitalisations for exacerbations in COPD patients. Eur Respir 7 2006;28:123-30.

11. Kodner DL, Kyriacou CK. Fully integrated care for frail elderly: two American models. Int 7 Integr Care 2000;1:e08.

12. Béland F, Bergman H, Lebel P, et al. A system of integrated care for older persons with disabilities in Canada: results from a randomized controlled trial. 7 Gerontol A Biol Sci Med Sci 2006;61:367-73.

13. Improving care for high-needs patients: McGuinty government linking health rroviders, offering patients more co-ordinated care [news release]. Toronto: Ministry of Health and Long-Term Care; 2012 Dec. 6. Available: https:// news.ontario.ca/mohltc/en/2012/12/improving-care-for-high-needs-patients .html (accessed 2017 Sep. 20).

14. Health Links. Grimsby (ON): Hamilton Niagara Haldimand Brant LHIN; 2014. Available: www.hnhblhin.on.ca/goalsandachievements/Sub-Regions and Health Links/healthlinks.aspx (accessed 2016 Dec. 12).

15. Health Links Coordinated Care Planning Toolkit. Grimsby (ON): Hamilton Niagara Haldimand Brant LHIN; 2016. Available: www.hnhblhin.on.ca/forhsps/ HealthLinkResources/CoordinatedCarePlanningToolkit.aspx (accessed 2016 Dec. 12).

16. Health Links. Toronto: Health Quality Ontario; 2018. Available: www. hqontario.ca/Quality-Improvement/Quality-Improvement-In-Action/Health -Links/ (accessed 2018 Mar. 12).

17. Partners in change: integrated decision support data warehouse and business intelligence solution. Grimsby (ON): Hamilton Niagara Haldimand Brant LHIN; 2014. Available: www.hnhblhin.on.ca/Resources/PartnersforChange. aspx (accessed 2016 Nov. 10).

18. Poole PJ, Chase B, Frankel A, et al. Case management may reduce length of hospital stay in patients with recurrent admissions for chronic obstructive pulmonary disease. Respirology 2001;6:37-42.

19. Olsson L-E, Karlsson J, Ekman I. The integrated care pathway reduced the number of hospital days by half: a prospective comparative study of patients with acute hip fracture. 7 Orthop Surg Res 2006;1:3.

20. Stokes J, Panagioti M, Alam R, et al. Effectiveness of case management for 'at risk' patients in primary care: a systematic review and meta-analysis. PLoS One 2015;10:e132340.

21. Protecting your privacy. Toronto: Health Shared Services Ontario; 2017. Available: http://hssontario.ca/Who/Pages/protecting-your-privacy.aspx (accessed 2018 Mar. 12).

22. National Ambulatory Care Reporting System (NACRS) metadata. Ottawa: Canadian Institute for Health Information (CIHI); 2016. Available: https:// www.cihi.ca/en/types-of-care/hospital-care/emergency-and-ambulatory-care/ nacrs-metadata (accessed 2016 Nov. 10).

23. Discharge Abstract Database metadata (DAD). Ottawa: Canadian Institute for Health Information (CIHI); 2016. Available: https://www.cihi.ca/en/types-of -care/hospital-care/acute-care/dad-metadata (accessed 2016 Nov. 10).

24. Concept: Charlson Comorbidity Index. Winnipeg: Manitoba Centre for Health Policy, University of Manitoba; 2016. Available: http://mchp-appserv. cpe.umanitoba.ca/viewConcept.php? conceptID=1098 (accessed 2017 Jan. 28).

25. ICD-10-CA (International Statistical Classification of Diseases and Related Health Problems, 10th revision, Canada). Ottawa: Canadian Institute for Health Information (CIHI); 2017. Available: https://www.cihi.ca/en/submit -data-and-view-standards/codes-and-classifications/icd-10-ca (accessed 2016 Dec. 12).

26. Determining the target population for health links: Q\&As in follow-up to the Aug. 12 webinar. Toronto: Ontario Ministry of Health and Long-Term Care; 2015 .

27. Vandenbroucke JP, von Elm E, Altman DG, et al.; STROBE Initiative. Strengthening the Reporting of Observational Studies in Epidemiology (STROBE): explanation and elaboration. PLoS Med 2007;4:e297.

28. Austin PC. Optimal caliper widths for propensity-score matching when estimating differences in means and differences in proportions in observational studies. Pharm Stat 2011;10:150-61.

29. Faries DE, Leon AC, Haro JM, et al., editors. Analysis of observational bealth care data using $S A S^{(R)}$. Cary (NC): SAS Institute Inc.; 2010.

30. Peikes D, Chen A, Schore J, et al. Effects of care coordination on hospitalization, quality of care, and health care expenditures among Medicare beneficiaries: 15 randomized trials. $7 A M A$ 2009;301:603-18.

Affiliations: Hamilton Niagara Haldimand Brant Local Health Integration Network (Bielska, Cimek, Hunter), Grimsby, Ont.; McMaster Family Practice (Guenter), Department of Family Medicine, McMaster University; Centre for Health Services and Policy Research (Bielska), Queen's University, Kingston, Ont.; Community and Population Health Services (O'Halloran), Hamilton Health Sciences; Integrated Decision Support (IDS) (Nyitray), Hamilton Health Sciences, Hamilton, Ont.; Institute of Health Policy, Management and Evaluation (Wodchis), University of Toronto, Toronto, Ont.; Institute for Better Health (Wodchis), Trillium Health Partners, Mississauga, Ont.

Contributors: All of the authors were involved in the concept and design of the study. Iwona Bielska drafted the manuscript, which all of the authors revised critically. All of the authors approved the final version to be published and agreed to act as guarantors of the work.

Acknowledgments: The authors thank the project leads and all providers involved in Hamilton Niagara Haldimand Brant Local Health Integration Network Health Links for their contributions, the Hamilton Niagara Haldimand Brant Local Health Integration Network Health Links Steering and Operations Committees and the Analytical Working Group.

Supplemental information: For reviewer comments and the original submission of this manuscript, please see www.cmajopen.ca/content/6/2/ E281/suppl/DC1. 